\title{
Does personality shape the personal social networks of older Europeans?
}

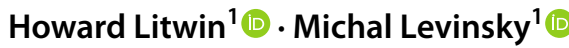

Accepted: 21 December 2021 / Published online: 6 January 2022

(c) The Author(s), under exclusive licence to Springer Nature B.V. 2022

\begin{abstract}
The aim of the study was to clarify whether personality traits predict the structure, function and quality of egocentric confidant networks in later life. Data were drawn from Waves 7 and 8 of the Survey of Health, Ageing and Retirement in Europe (SHARE) $(N=39,172)$. We regressed network size, contact frequency and network satisfaction on the Big-5 personality traits, using a single path analysis structure, controlling for country, sociodemographic background and health status. The findings showed that the personality traits were related to the social network outcomes, but their effect was modest and less predictive than the contextual factors. The country predictors explained the most variance, generally, with some surprising results. For example, confidant networks were the largest in Scandinavia and Central Europe, and smallest in the Mediterranean region and Eastern Europe. Among the personality traits, extraversion was the most consistent positive predictor, but conscientiousness was also predictive. Neuroticism was a negative predictor, but not of network size. The sociodemographic variables, particularly partner status, explained more variance than the personality traits did. In sum, the SHARE database offers a comprehensive and differentiated view of the complex interpersonal milieus in which older Europeans are embedded.
\end{abstract}

Keywords Extraversion $\cdot$ Conscientiousness $\cdot$ Network size $\cdot$ Contact frequency $\cdot$ SHARE

\section{Introduction}

It is well known that the social networks of older people provide their focal members with a range of supports that contribute significantly to their well-being (Litwin 2010; Rafnsson et al. 2015). It is also known, however, that social networks tend to vary across different individuals, in terms of their structure, function and quality (Berkman et al. 2000; Kohli et al. 2009; Unger et al. 1999). Thus, not everyone benefits in the same way, or to the same degree, from the inter-personal constellation in which he or she is embedded. What is it that accounts for the differences that may emerge in social network structure, function and/or quality in later life?

Responsible Editor: Matthias Kliegel.

Michal Levinsky

michal.levinsky@mail.huji.ac.il

1 Israel Gerontological Data Center, Paul Baerwald School of Social Work and Social Welfare, The Hebrew University of Jerusalem, Mount Scopus, Jerusalem, Israel
In order to shed light on this research question, we look particularly at the role of personality in the shaping of personal social networks, alongside the effects of contextual factors. We examine the associations between five main personality characteristics and selected key indicators from the domain of social networks. Our investigation seeks to clarify what matters more in the shaping of the interpersonal milieu of older adults-is it their personality that primarily affects the formation of their network or, rather, contextual factors such as socioeconomic background, health and cultural context?

The Survey of Health, Ageing and Retirement in Europe (SHARE) uniquely provides the capacity to consider this question in a cross-cultural European context (Börsch-Supan et al. 2013). In its seventh wave (2018), SHARE introduced a brief version of the renowned Big- 5 Inventory (Rammstedt and John 2007). The eighth wave of the survey (2019-2020, before the outbreak of COVID-19) re-administered the special social network module that was developed for SHARE (Litwin et al. 2013). The module provides a tool that is designed to derive respondents' personal social networks, or confidant networks (Litwin and Stoeckel 2014). Based on these data, we were able to investigate the unique role of 
personality, vis a vis the personal social network that was reported by each respondent some two years hence, controlling for socioeconomic background, health status and country.

\section{Literature review}

Personality traits reflect the most characteristic patterns of thinking, feeling and behaving that prevail among different people (Erlich and Litwin 2019). Such attributes and, particularly, age-related differences in personality patterns have been the focus of research attention for decades. A fivefactor structure of personality, that was first introduced in the late 1980s, stands until today as the prevailing conceptual construct for the identification and understanding of individual personality differences (John and Srivastava 1999; Lang et al. 2001). The five factors, widely known as "the Big Five", include: (1) openness to experience (vs. closedness), (2) conscientiousness (vs. lack of direction), (3) extraversion (vs. introversion), (4) agreeableness (vs. antagonism) and (5) neuroticism (vs. emotional stability). A review of the literature reveals that personality traits are variously related to a range of important outcomes in late life, including morale (Loke et al. 2011), successful aging (Dumitrache et al. 2019), cognition (Cerino et al. 2020; Colombo et al. 2020; Power et al. 2017), loneliness (von Soest et al. 2020) and mortality (Rizzuto et al. 2017).

Social networks are the sets of social ties that people variously maintain over the life course, and from which they may obtain a variety of benefits, including emotional support, affirmation, concrete assistance and socialization (Litwin 2010). These social constellations are complex entities, however, and they reflect a range of characteristics. Much of contemporary gerontological research in this domain focuses upon three key aspects of the social network, namely, network structure, function and quality (Huo et al. 2020). In addition, a large part of recent research concentrates on the personal social network (or egocentric network), that is, the specific collection of social ties that are most meaningful to a given person (Cornwell et al. 2009). Different aspects of the social network are variously related to outcomes of gerontological interest, such as life satisfaction (Rafnsson et al. 2015), resilience (Park et al. 2021), psychological distress (Phongsavan et al. 2013) and mortality (Ellwardt et al. 2015; Lund et al. 2000).

Personality attributes are also related, to varying degrees, to social network structure, function and/or quality (Grieve and Kemp 2015; Hall et al. 2020; Huo et al. 2020; Lincoln et al. 2003). As for the five main personality traits, noted earlier, the most examined trait in relation to network structure, function and quality is, perhaps, extraversion. Thus, for example, a study based on social network data from the National Social life, Health and Aging
Project (NSHAP) in the US found that extraversion (as well as agreeableness) was related to what the investigator called "tie strength," and it was also weakly associated with friend network size (Iveniuk 2019). In an earlier study in West Berlin of adults, aged 70 to 104, extraversion correlated with overall network size (Lang et al. 1998). Analysis of an Irish sample revealed that extraversion in that sample was among the predictors of social support, a network function measure (Schnittger et al. 2012). Finally, a study of older Facebook users found that those with a high level of extroversion (and openness) had a greater number of Facebook friends and group memberships (Mo et al. 2018).

There is somewhat less research reported on the association between the trait of conscientiousness and network structure, function or quality. One study of depressed older people in Northern Germany found that higher levels of conscientiousness correlated with help-seeking for depression, while none of the other personality traits were associated with this same network function variable (Schomerus et al. 2013). On the other hand, curiously, in the study of older Facebook users that was cited above, those having a high level of conscientiousness had fewer "likes" (Mo et al. 2018).

The assumed effect of neuroticism on social network is usually negative. Thus, for example, in the study by Lang and others (1998), neuroticism correlated negatively with network size. Similarly, in a study of older Black Americans, neuroticism was identified as a correlate of negative interaction with relatives and friends (Lincoln et al. 2003). Neuroticism was also included in the previously mentioned Irish study as a predictor of both emotional and social loneliness (Schnittger et al. 2012). In comparison, Iveniuk (2019) found that more-neurotic persons were more likely to talk about their health with friends, thus pointing to a potentially positive network function. A Dutch study found neuroticism to be related to loneliness among women, but no association between neuroticism and network size (Schutter et al. 2020).

Network structure, function and quality are related to a range of contextual factors as well. These include such socioeconomic variables as age, gender and income (Antonucci et al. 2015), education (Van Groenou and Van Tilburg 2003) and marital status (Torres et al. 2016); health status variables (Ha et al. 2017; Macias et al. 2013); and national or cultural context (Ajrouch et al. 2018). Consequently, these background factors must also be taken into account.

Given the range of findings in this area, we are unable to posit specific research-based hypotheses in our present inquiry. Instead, our analysis is guided by the following general research questions:

1. Do personality traits and contextual factors (socioeconomic background, health status, and country) shape the 
personal social network of older Europeans to the same degree?

2. Are personality traits differentially related to social network structure, function and quality?

2A. Do extraverted older Europeans have more social ties (i.e. larger social networks)?

2B. Do neurotic older Europeans have fewer social ties?

3. Which socioeconomic background and health status variables are most related to social network structure, function and quality in later life?

4. Are there country differences vis a vis social network structure, function and quality among older Europeans?

\section{Method}

\section{Sample}

The study draws upon data from SHARE, a major longitudinal survey of persons aged 50 and over, and their spouses of any age (Börsch-Supan et al. 2013). The initial baseline study sample (Wave 7, 2018) included 72,701 respondents, aged 50 or older, who had the requisite personality data. This wave provided several of the sociodemographic variables as well. SHARE Wave 8 (2019-2020) added the three network outcome variables, and the marital and health status indicators, insofar as these latter background statuses may have changed since the previous wave. The number of respondents having the necessary data from both the waves under consideration totaled 39,172 persons from 26 countries (See Table 1 for the full list of countries).

The large attrition in Wave $8(n=33,529)$ is explained mostly by the fact that SHARE data collection was necessarily stopped, early in 2020, due to the outbreak of the COVID-19 pandemic. Some 30,599 Wave 7 respondents were missing from Wave 8 due to the early cessation of data collection, or to natural dropout that occurs between waves in longitudinal studies. A small number of respondents died after Wave $7(n=2,448)$, or were missing the social network data in Wave $8(n=482)$. We performed $T$-tests to compare the background and health variables across the two groups, that is, the study participants and the dropouts. The comparison revealed several differences.

Specifically, the mean age of those in the analytic sample was a bit younger than the mean age of those in the attrition group (67.8 and 68.0, respectively, $t=-3.7, \mathrm{p}<0.001$ ), they had slightly higher education (3.00 and 2.82, $t=16.9$, $p<0.001)$, and moderately better financial capacity ( 2.81 and $2.69, t=15.5, p<0.001)$. There were also slightly more women in the sample (58\%) compared to the attrition group (56\%; $t=5.3, p<0.001)$. Partner status did not differ between the two groups. Finally, those in the sample had somewhat fewer mobility difficulties than those in the attrition group (1.55 and 1.84, respectively, $t=-16.2$, $p<0.001)$, and slightly better self-rated health (2.80 and $2.69, t=14.6, p<0.001)$.

We note, therefore, that although the analytic sample was quite large and contained all the information that was required for the current inquiry, the study sample was not perfectly representative of all people aged 50 and over in Europe and Israel. In addition, we note that 635 of the study sample members $(1.6 \%)$ were missing data on one or more of the background and health variables. Their missing data were imputed by means of a full information maximum likelihood (FIML) estimator.

\section{Variables}

Personality traits were measured using a brief version of the Big-Five Inventory that was administered in SHARE in 2018. The BFI-10 is a ten-item measure that is suitable for comprehensive surveys in which interview time is limited. Earlier examinations have shown that the brief version obtains sufficient reliability (Rammstedt and John 2007). We note that following the data collection in SHARE Wave 7 , dimensionality analyses were performed to determine whether the five expected dimensions did indeed emerge in the SHARE sample. The test results for the pooled sample found a strong congruency between the idealized Big-Five structure and the actual scores $(c=0.94)$ (Levinsky et al. 2019).

The BFI-10 includes two statements (one positive and one negative) for each of the five personality traits: (1) openness, (2) conscientiousness, (3) extraversion, (4) agreeableness, and (5) neuroticism. An example of the positively worded indicator of extraversion was "I see myself as someone who is outgoing, sociable." The corresponding negative indicator of extraversion was "I see myself as someone who is reserved." Respondents were asked to indicate the degree of agreement with each statement on a 5-point scale. SHARE has generated five corresponding personality trait variables from the raw data, in order to facilitate their use in research. The score on each such variable is the mean of the pair of respective items (one reverse-coded).

Personal social network variables were obtained from the name generator network inventory that was administered in SHARE Wave 8. Respondents were asked to cite up to six people with whom they discussed matters of importance in the previous year, and a seventh who may have been important for any other reason (Litwin et al. 2013). The SHARE name generator is based upon the one that is employed in the National Social life, Health and Aging Project in the United States (Cornwell et al. 2009). 
Table 1 Europeans aged 50 and older: Univariate description of the sample variables and background characteristics $(N=39,172)$

\begin{tabular}{|c|c|c|c|c|c|c|}
\hline Characteristic & & $N$ & $\%$ & Mean & SD & Range \\
\hline \multirow[t]{2}{*}{ Gender } & Men & 16,520 & 42.2 & & & \\
\hline & Women & 22,652 & 57.9 & & & \\
\hline \multirow[t]{2}{*}{ Marital status } & No Live-in partner & 12,441 & 32.0 & & & \\
\hline & Live-in partner & 26,731 & 68.0 & & & \\
\hline \multirow[t]{26}{*}{ Country } & Austria & 1386 & 3.54 & & & \\
\hline & Belgium & 1852 & 4.73 & & & \\
\hline & Bulgaria & 846 & 2.16 & & & \\
\hline & Croatia & 1093 & 2.79 & & & \\
\hline & Cyprus & 453 & 1.16 & & & \\
\hline & Czech Republic & 2410 & 6.15 & & & \\
\hline & Denmark & 2001 & 5.11 & & & \\
\hline & Estonia & 2674 & 6.83 & & & \\
\hline & Finland & 1075 & 2.74 & & & \\
\hline & France & 2178 & 5.56 & & & \\
\hline & Germany & 2740 & 6.99 & & & \\
\hline & Greece & 1931 & 4.93 & & & \\
\hline & Hungary & 654 & 1.67 & & & \\
\hline & Israel & 699 & 1.78 & & & \\
\hline & Italy & 1929 & 4.92 & & & \\
\hline & Latvia & 708 & 1.81 & & & \\
\hline & Lithuania & 1309 & 3.34 & & & \\
\hline & Luxembourg & 785 & 2.00 & & & \\
\hline & Malta & 723 & 1.85 & & & \\
\hline & Poland & 1851 & 4.73 & & & \\
\hline & Romania & 1175 & 3.00 & & & \\
\hline & Slovakia & 928 & 2.37 & & & \\
\hline & Slovenia & 2141 & 5.47 & & & \\
\hline & Spain & 1785 & 4.56 & & & \\
\hline & Sweden & 2080 & 5.31 & & & \\
\hline & Switzerland & 1766 & 4.51 & & & \\
\hline Age & & & & 67.8 & 9.1 & $50-101$ \\
\hline Education & & & & 3.0 & 1.4 & $0-6$ \\
\hline Financial capacity & & & & 2.8 & 1.0 & $1-4$ \\
\hline Mobility difficulty & & & & 1.8 & 2.4 & $0-10$ \\
\hline Self-rated health & & & & 2.8 & 1.0 & $1-5$ \\
\hline \multirow[t]{5}{*}{ Personality } & Openness & & & 3.3 & 1.0 & $1-5$ \\
\hline & Conscientiousness & & & 4.1 & 0.8 & $1-5$ \\
\hline & Extraversion & & & 3.5 & 0.9 & $1-5$ \\
\hline & Agreeableness & & & 3.7 & 0.8 & $1-5$ \\
\hline & Neuroticism & & & 2.6 & 1.0 & $1-5$ \\
\hline \multirow[t]{3}{*}{ Social network } & Network size & & & 2.7 & 1.6 & $0-7$ \\
\hline & Contact frequency & & & 6.0 & 1.2 & $1-7$ \\
\hline & Network satisfaction & & & 9.0 & 1.4 & $0-10$ \\
\hline
\end{tabular}

As noted earlier, the present analysis considers the structure, function and quality of the personal network. These are distinct domains. The specific respective measures employed here were network size (structure), contact frequency (function) and satisfaction with the network (quality). We consider contact frequency to be a measure of network function unlike as in an earlier cited source, which classifies it as an indicator of network structure (Huo et al. 2020). In our opinion, contact frequency is a measure of the interaction that takes place among the network members, that is, of how the network functions. 
Operationally, network size was a simple count of the cited confidants, $0-7$. Contact frequency was measured as the mean on a 7-point scale; the higher the mean score, the more frequent the contact. [Those with no cited confidants were assigned the lowest score on contact frequency-one (never)]. Network satisfaction was tapped on a scale from 0 to 10 , the higher the score, the greater the satisfaction. Respondents with no named confidants were also asked in the survey how satisfied they were with their (lack of) social contacts, and thus, scores were available for them on this variable as well.

Background baseline sociodemographic variables in the analysis included age, gender (male $=0$, female $=1$ ), education (ranked on the ISCED scale of 0-6, the higher the score, the greater the education) and financial capacity, measured on a 4-point scale of the perceived difficulty in making ends meet (a higher score indicates fewer such difficulties). This perceived financial capacity measure has been shown to adequately reflect key income differentials (Litwin and Sapir 2009).

We also controlled for marital status (no live-in partner $=0$, live-in partner $=1)$, mobility difficulties $(0-10$; the higher the score the greater the difficulty) and self-rated health (the higher the score, the better one's self-perceived health). As noted earlier, these particular control variables were taken from SHARE Wave 8. Country of residence was utilized as a measure of national character or culture. The country indicator was taken into account by means of dichotomous dummy variables and effect coding.

\section{Analysis}

The analysis began with univariate descriptions of the variables in the present sample, and examination of the bivariate associations among them, using Stata 15. In the multivariate part of the analysis, we regressed the respective network variables (size, contact frequency and network satisfaction) on the study variables using a single path analysis structure. By entering the regression equations together, it is possible to estimate residual covariances among the dependent variables. The path analysis was performed by means of the lavaan package in R, version 4.0.3 (See Supplementary File 2 - path analysis code in R).

The path analysis regressions proceeded in three stages. First, the network outcomes were regressed on the sociodemographic variables, including marital status and country. The second model added the two health variables-mobility difficulty and self-rated health. In the third and final stage, the network measures were regressed on the five personality traits, controlling for the effects of the other study variables. In order to further clarify the net country effects vis a vis the network outcomes, we graphed the effect-coded country contrasts.

\section{Results}

The sample had a majority of women (58\%) and a mean age of 68 years, at baseline. About two thirds had a livein partner. Mean education level was secondary school. The average respondent in the sample had good financial capacity, relatively few mobility limitations, and moderately good health. The most prevalent personality trait among the respondents was conscientiousness and the least prevalent was neuroticism. Respondents had, on average, almost three confidants. Contact with the personal social network was relatively frequent, overall, and satisfaction from the network was quite high.

The bivariate correlations revealed that almost all the study variables were related to the respective network outcome measures (see Supplementary Table 1). Thus, among the personality traits, openness, conscientiousness, extraversion and agreeableness were positively related to network size and network satisfaction, while neuroticism was negatively related. As for contact frequency, conscientiousness, extraversion and neuroticism were positively associated, but openness and agreeableness were negatively associated.

In terms of the contextual variables, age was negatively related to all three of the network outcomes. Female gender, education, financial capacity were all positively related to network size and network satisfaction, and negatively so to contact frequency. Partner status was positively correlated with all three of the network outcomes. Mobility difficulties were negatively associated with network size and satisfaction, while self-rated health was positively associated. Of the two health variables, only self-rated health was negatively associated with contact frequency. The vast majority of the country dummy variables were related, whether positively or negatively, to the respective network variables.

Table 2 presents the results of the multivariate analyses that were executed by means of the single path analysis structure. In Model 1A, network size was regressed on the background variables. As may be seen, all the variables were positively associated with this network outcome, except for age, which was negatively related. The model accounted for 14 percent of the variance. Model 1B added the health variables, both of which were positively associated with network size. The associations of the other variables in the model and the explained variance remained about the same. In Model 1C, we see that the addition of the personality traits added one more percentage point to the explained variance, and that three of the traits (openness, extraversion and agreeableness) were significant, 
Table 2 Background, health and personality predictors of personal social networks among Europeans aged $50+:$ Regression equations by path analysis $(N=39,172)$

\begin{tabular}{|c|c|c|c|c|c|c|c|c|c|}
\hline \multirow[b]{2}{*}{ Variables $^{\mathrm{A}}$} & \multicolumn{3}{|l|}{ Network size } & \multicolumn{3}{|c|}{ Contact frequency } & \multicolumn{3}{|c|}{ Network satisfaction } \\
\hline & $\begin{array}{l}\text { Model 1A } \\
\beta\end{array}$ & $\begin{array}{l}\text { Model 1B } \\
\beta\end{array}$ & $\begin{array}{l}\text { Model 1C } \\
\beta\end{array}$ & $\begin{array}{l}\text { Model 2A } \\
\beta\end{array}$ & $\begin{array}{l}\text { Model 2B } \\
\beta\end{array}$ & $\begin{array}{l}\text { Model 2C } \\
\beta\end{array}$ & $\begin{array}{l}\text { Model 3A } \\
\beta\end{array}$ & $\begin{array}{l}\text { Model 3B } \\
\beta\end{array}$ & $\begin{array}{l}\text { Model 3C } \\
\beta\end{array}$ \\
\hline Age & $-0.020 * * *$ & $-0.018^{* *}$ & $-0.020 * * *$ & $-0.024 * * *$ & $-0.024 * * *$ & $-0.026 * * *$ & $-0.018 * *$ & 0.007 & -0.001 \\
\hline Gender $(F)$ & $0.139 * * *$ & $0.136 * * *$ & $0.129 * * *$ & $0.014 * *$ & $0.021 *$ & $0.013 *$ & $0.070 * * *$ & $0.072 * * *$ & $0.069 * * *$ \\
\hline Partner & $0.095 * * *$ & $0.096^{* * *}$ & $0.096 * * *$ & $0.222 * * *$ & $0.222 * * *$ & $0.222 * * *$ & $0.087 * * *$ & $0.086^{* * *}$ & $0.087 * * *$ \\
\hline Education & $0.091 * * *$ & $0.088 * * *$ & $0.079 * * *$ & $-0.064 * * *$ & $-0.065 * * *$ & $-0.058 * * *$ & 0.008 & -0.005 & -0.007 \\
\hline Financial capacity & $0.052 * * *$ & $0.049 * * *$ & $0.047 * * *$ & $-0.015^{*}$ & $-0.016^{*}$ & $-0.017 * *$ & $0.066 * * *$ & $0.048 * * *$ & $0.041 * * *$ \\
\hline Mobility difficulty & & $0.030 * * *$ & $0.030 * * *$ & & $0.015^{*}$ & $0.017 * *$ & & $-0.016^{*}$ & -0.009 \\
\hline SRH & & $0.046^{* * *}$ & $0.037 * * *$ & & $0.020 * *$ & $0.015^{*}$ & & $0.083 * * *$ & $0.062 * * *$ \\
\hline Openness & & & $0.055^{* * *}$ & & & $-0.033 * * *$ & & & $0.021 * * *$ \\
\hline Conscientiousness & & & 0.006 & & & $0.026 * * *$ & & & $0.065^{* * *}$ \\
\hline Extraversion & & & $0.04 * * *$ & & & $0.024 * * *$ & & & $0.045^{* * *}$ \\
\hline Agreeableness & & & $0.052 * * *$ & & & 0.006 & & & $0.051 * * *$ \\
\hline Neuroticism & & & -0.003 & & & $-0.016^{* *}$ & & & $-0.062 * * *$ \\
\hline R-squared & 0.140 & 0.141 & 0.150 & 0.132 & 0.133 & 0.135 & 0.040 & 0.047 & 0.064 \\
\hline
\end{tabular}

A All models controlled for country

$* p<0.05, * * p<0.01$, *** $p<0.001$

each with a positive association with network size. The other two traits, however, were unrelated. The effects of the other variables in the model remained significant.

In Model 2A, mean contact frequency was regressed on the background variables. In this case, age education and financial capacity showed negative associations, while female gender and live-in partner were positive. This model explained some 13 percent of the variance. Model 2B reveals that both mobility difficulty and self-rated health were positively related to the contact outcome. The explained variance of the model remained almost the same. In Model 2C, all the personality traits, except for agreeableness, were significant. Openness and neuroticism were negatively associated with contact frequency, while conscientiousness and extraversion were positively related. This last model added less than one percentage point to the explained variance, however. The effects of the other variables in the model remained about the same.

The final models $(3 \mathrm{~A}-3 \mathrm{C})$ regressed the network satisfaction measure on the respective study variables. In Model $3 \mathrm{~A}$, we see that female gender, partner status and financial capacity were positively related to network satisfaction. The age variable on the other hand, was negatively related. This model accounted for only a small amount of the variance, about 4 percent.

Model 3B added the health variables to the regression. In this case, mobility difficulty was negatively associated with network satisfaction while self-rated health was positively associated. Among the background variables, only gender, partner status and financial capacity retained their previous significance. We note that this model added less than a percentage point to the explained variance. Finally, the addition of the personality traits to the regression (Model 3C) increased the explained variance by almost two additional percentage points. The model shows that four of the personality traits were positively associated with the network quality outcome measure, and that the fifth-neuroticism-was negatively related. The effects of the other variables that were significant in the previous model remained significant in the current model, except for mobility difficulty.

Figure 1 presents the country effects in relation to the respective network outcome measures. The grey bars at the top of each graph reflect those countries in which the mean network measure in question was above the overall mean for all the countries. The light grey bars at the bottom represent countries in which the mean network was below the overall mean. The black bars in the middle are for countries that did not diverge significantly from the overall mean. From among the many possible observations, we note the following.

The largest personal social networks, after controlling for background, health and personality factors, were reported in Scandinavia (Finland, Sweden) and Central Europe (Austria, Belgium, Germany). The smallest were observed in two Mediterranean island countries (Malta, Cyprus) and Eastern Europe (Latvia, Slovakia, Lithuania). As for contact frequency, the countries whose residents had the most frequent mean contact with their personal social networks were from the Mediterranean region (Greece, Cyprus, Italy). Those with the least frequent mean contact were Scandinavian (Finland, Sweden, 


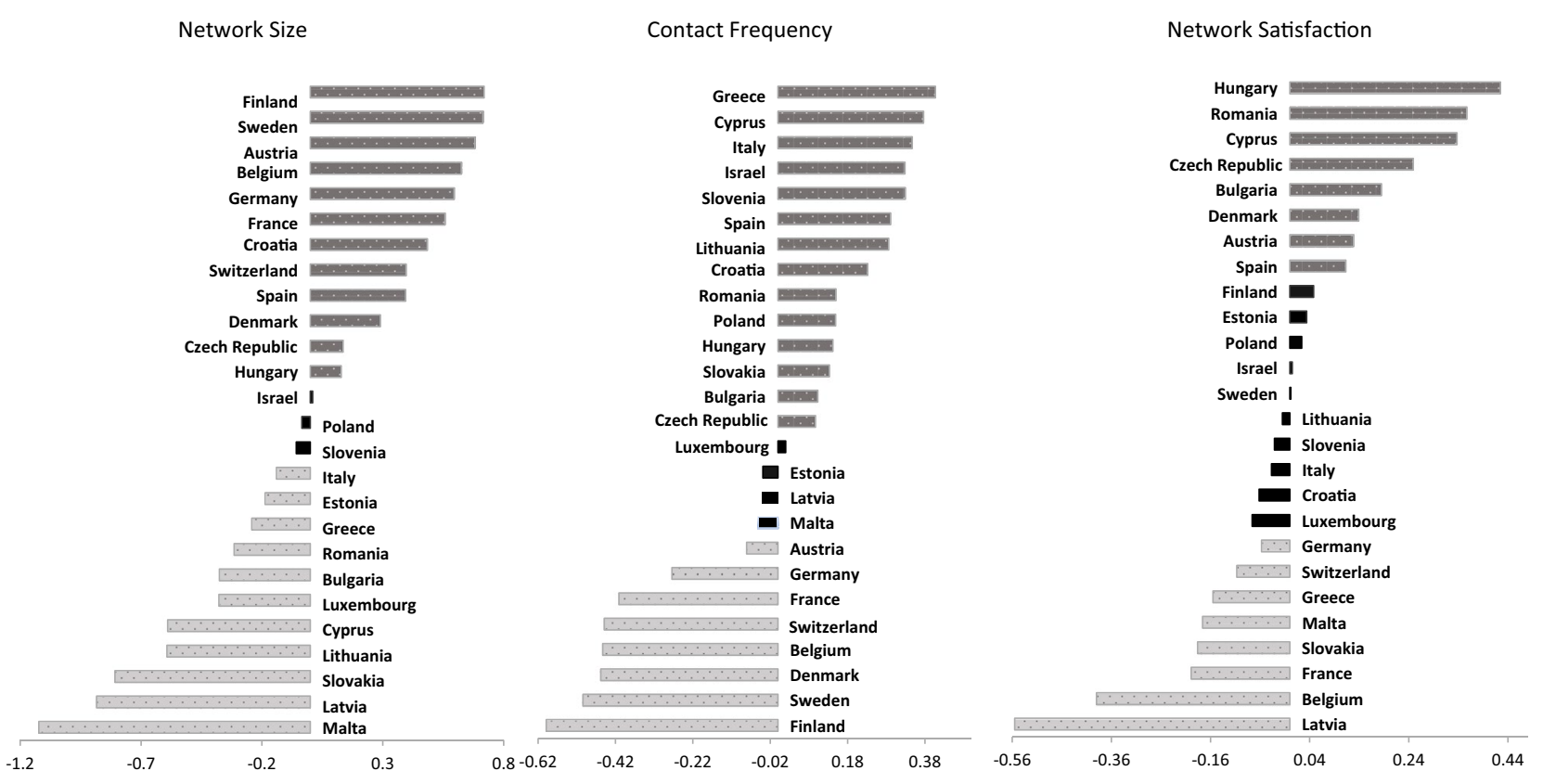

Fig. 1 Net effects of country of residence on network size, contact frequency and network satisfaction: Effect coded country contrasts

Denmark) or Central European (Belgium, Switzerland). The countries in which the greatest mean degree of satisfaction with the network was reported were primarily from Eastern Europe (Hungary, Romania, Czech Republic, Bulgaria), and Cyprus. The countries whose respondents were the least satisfied with their networks came from a variety of regions: Latvia and Slovakia (Eastern Europe), Belgium and France (Central Europe) and Malta and Greece (the Mediterranean).

In order to estimate the relative explanatory power of "country" compared to that of the sociodemographic variables, we ran a supplementary series of regressions, here too using a single path analysis structure (see Supplementary Table 2). For network size, the variance explained by country was about 10 percent, while the addition of the sociodemographic variables increased the explained variance by another three and a half points. Country explained more than eight percent of the variance in contact frequency, and the sociodemographic variables added another five percent. In the network satisfaction measure, country accounted for two and a half percent of the variance while the background variables added another one and a half more points. These statistics show that country was the most predictive among the contextual variables. They also confirm, nevertheless, that the sociodemographic variables explained more of the variance than did the personality traits (for network size and contact frequency) or about the same amount of the variance (for network satisfaction).

Finally, concerning the covariances between the network measures themselves, mean contact frequency was negatively related to network size, albeit weakly (standardized cov $=-0.076, p<0.001$ ). Network satisfaction correlated positively with both network size (standardized $\operatorname{cov}=0.091, p<0.001$ ) and mean contact frequency (standardized $\operatorname{cov}=0.335, p<0.001$ ).

\section{Discussion}

This study used data from two consecutive waves of SHARE, in 2018 and 2020, to clarify the extent to which personality shapes the personal social networks of older Europeans. The inquiry also addressed a number of related questions of interest. The first research question was "do personality traits and contextual factors (socioeconomic background, health status and country) shape the personal social network of older Europeans to the same degree?" The main finding that emerged from the analysis was that although many personality traits are, indeed, significantly related to key selected social network outcomes, their effect was modest, at most, and they were usually less explanatory than were the contextual factors.

As such, this longitudinal study of a large sample of older adults from 25 European countries and Israel provides important empirical backing to the results of an earlier study that was based upon a small cross-sectional German sample. In that study, the investigators found a stronger influence of contextual rather than personality factors on social functioning in late life (Lang et al. 1998). In our present analysis, we examined the correlates of three aspects of the 
personal social network: size, contact frequency and network satisfaction. These particular measures reflect each of the three key domains of the network phenomenon, namely network structure, function and quality. In each of these domains, the personality traits added only a relatively small amount to the explained variance. They explained more of the variance than did health status, but less than the variance accounted for by the sociodemographic background and country variables.

We also examined whether different personality characteristics relate differently to social network structure, function and quality. In this regard, we considered two specific research questions. First, do extraverted older Europeans have a greater number of confidants, that is, do they have larger personal social networks? We assumed that they would, insofar as this particular personality trait exudes sociability, activity, and assertiveness (Erlich and Litwin 2019). The multivariate analysis confirmed the association between extraversion and network size, although it was rather weak. Interestingly, two other personality traits had slightly stronger positive associations with network sizeopenness and agreeableness. More research on these two traits is warranted. Extraversion also positively correlated with contact frequency and network satisfaction. Moreover, it was the only personality trait among the five to achieve a significant positive correlation with all three of the network outcomes in the study, after controlling for the effects of the other study variables. It seems, therefore, that extraversion is, indeed, the most consistent personality predictor of meaningful social connectedness in all its facets among older Europeans, even if the effect, per se, is rather small.

Insofar as neuroticism is characterized by tension, anxiety and the tendency to be temperamental (Erlich and Litwin 2019), we queried whether neurotic older Europeans would have fewer confidants. Although we expected a negative relationship to exist between neuroticism and network size, the regression analysis showed that there was no association at all between the two indicators, after controlling for the other study variables. That is, the results showed that older Europeans with neurotic personality traits did not necessarily name significantly fewer confidants. On the other hand, neurotic personality types did have a lower mean frequency of contact with their most intimate social ties, perhaps due to these neurotic tendencies. They also reported less satisfaction from their social networks.

We should add a word on the trait of conscientiousness. A research question was not posed in relation to this particular personality trait due to the dearth of relevant research findings. Nevertheless, one recent study in this domain provides some insight concerning the findings on conscientiousness in the present analysis. Drawing on data from the Health and Retirement Study in the United States, Steptoe and Jackson (2018) defined conscientiousness as one of five life skills that lead to better individual functioning over all, and to better social functioning in particular. They found, in their analytical sample (mean age $=73$ ), that having more life skills was associated with stronger social relationships. This conclusion parallels the findings in the current study. Europeans with greater conscientiousness did not report having a greater number of confidants (network size), but they did have greater contact frequency and greater satisfaction from the social ties that they maintained. In other words, conscientiousness did not increase the number of close ties that one had, but it did seem to strengthen the interaction with them as well as the quality of the relationships.

Our next research question asked which of the socioeconomic background and health status variables were most related to social network structure, function and quality in later life. We found that female gender and marital status were the only such variables to be positively related to all of the network outcomes: size, contact frequency and network satisfaction. Thus, gender and having a live-in partner were the most consistent background factors that framed the personal social networks of older Europeans. Financial capacity was positively associated with network size and satisfaction, but negatively related to mean network contact frequency, albeit weakly. The education variable behaved almost the same, but it had no association with network satisfaction when the other study variables were controlled.

Age correlated negatively with network size and contact frequency, overall. However, it was unrelated to network satisfaction, despite the possible differences in network size and contact frequency in late life. The findings thus suggest that the quality of one's closest interpersonal milieu does not necessarily diminish with advancing age.

As for health status, better self-rated health was positively related to all the network outcomes. This finding underscores the positive association found in the literature between good health and social connectedness (Ashida and Heaney 2008). Our measure of ill-health (mobility difficulties), although negatively related to network size at the bivariate level [as was found in an American study using data from NSHAP (Schafer 2018)], was positively related to network size and contact frequency in the multivariate procedure. It could be that one's disability status increases the need for personal assistance and, hence, both the number of confidants and the frequency of contact with them. This latter finding echoes that of another study, which found that severe health conditions were associated with a more frequent rate of family contact (Macias et al. 2013).

The last research question queried whether there are country differences in social network structure, function and quality among older Europeans. The results showed that country differences did prevail, suggesting that national or cultural context does shape one's personal social network in 
late life (Ajrouch et al. 2018). Space does not allow discussion of all the country variations that emerged. We highlight, therefore, a few salient findings.

The clearest differences were evident in terms of network size. The largest personal networks were in Scandinavia and Central Europe while the smallest were observed in the Mediterranean region and Eastern Europe. These results counter the popular belief that Scandinavians are loners while supportive families surround Southern Europeans. Our findings show that where confidants are concerned, older people in North and Central Europe have larger networks.

As for contact frequency, the greatest mean frequency was observed in Mediterranean countries, specifically Greece, Cyprus and Italy, after controlling for the effects of the other study variables. The lowest frequency was reported in the North and in the Central part of Europe. This finding corresponds to that of another study that claimed that the social contact frequency gap is larger in familialistic countries with strong filial norms (Baranowska-Rataj and Abramowska-Kmon 2019).

Finally, respondents in certain Eastern European countries (and Cyprus) reported the greatest extent of network satisfaction. This was due, perhaps, to minimal expectations in some former Soviet-Bloc countries for the receipt of support from public social welfare institutions. In comparison, the least degree of satisfaction with one's confidants was seen in some other Eastern Europe countries, as well as in certain Mediterranean countries. This last observation adds to what we hinted at earlier, namely, that network quality is a somewhat complicated phenomenon to predict.

The analysis also showed that the three network outcomes were partially inter-related beyond the effects of the model variables, but not uniformly so. Specifically, mean network contact frequency and network satisfaction were inter-correlated positively, as were network size and network satisfaction. However, network size correlated negatively with mean contact frequency. These findings raise an important observation. That is, although the respective network measures were partially inter-related, their covariances were not high. This underscores what the literature maintains, namely that network structure, function and quality are separate domains.

A few limitations of the present research should be noted. First, is the large attrition of the panel that occurred in Wave 8 , largely due to the pandemic. Our comparisons showed that the dropouts were slightly older, sicker, less educated and less well off financially than the study sample participants were. Consequently, we should qualify that the findings may be more reflective of the better-off older population. That said, we note that the panel still provided a very large and diverse sample that facilitated the present analysis.

A second potential limitation is that short measures of the Big Five, such as the one used in this study, may be unreliable within some countries. We did note earlier, however, that the results for the pooled sample were substantiated (Levinsky et al. 2019). Moreover, the personality variables were not considered at the country level, in the current analysis. Thus, despite potential shortcomings of brief personality inventories, their use in large-scale surveys such as SHARE provide reasonable and unprecedented analytical opportunities.

In conclusion, the present study contributes to the literature on the inter-relationship between personality factors and social connectedness in late life. We looked at the most intimate of interpersonal constellations-the personal social network, and found that personality traits do predict key network outcomes, albeit to a minor degree. Our analysis underscored the positive role of extraversion in relation to network structure, function and quality, and largely confirmed the negative role of neuroticism. Conscientiousness emerged as an additional positive, if understudied, factor in relation to personal social network. Future research should give more attention to this particular network trait in late life. Finally, openness and agreeableness revealed significant but mixed associations with the respective network outcome variables. Consequently, they both warrant further exploration.

The analysis also showed that the respective network domains that were addressed in the current study (structure, function and quality) were weakly inter-related. This finding underscores what the literature maintains, namely that the social network is a multi-faceted phenomenon. Hence, investigators should examine its dimensions individually, taking into account their potential covariances as well. The study also points to the need for the development of new assessment tools in order to translate the emerging knowledge about the personality-network nexus into practical means of intervention and treatment. Given the complexity of the association patterns that were observed in the current study, such refined assessment tools would be a useful addition to the field of practice.

Supplementary Information The online version contains supplementary material available at https://doi.org/10.1007/s10433-021-00678-8.

Funding The SHARE data collection has been funded by the European Commission through FP5 (QLK6-CT-2001-00360), FP6 (SHARE-I3: RII-CT-2006-062193, COMPARE: CIT5-CT-2005-028857, SHARELIFE: CIT4-CT-2006-028812), FP7 (SHARE-PREP: GA N²11909, SHARE-LEAP: GA N²27822, SHARE M4: GA N²61982, DASISH: GA ${ }^{\circ} 283646$ ) and Horizon 2020 (SHARE-DEV3: GA N 676536 , SHARE-COHESION: GA N870628, SERISS: GA N ${ }^{\circ} 654221$, SSHOC: GA $N^{\circ} 823782$ ) and by DG Employment, Social Affairs \& Inclusion. Additional funding from the German Ministry of Education and Research, the Max Planck Society for the Advancement of Science, the U.S. National Institute on Aging (U01_AG09740-13S2, P01_ AG005842, P01_AG08291, P30_AG12815, R21_AG025169, Y1-AG4553-01, IAG_BSR06-11, OGHA_04-064, HHSN271201300071C) and from various national funding sources is gratefully acknowledged (see www.share-project.org). 


\section{References}

Ajrouch KJ, Fuller HR, Akiyama H, Antonucci TC (2018) Convoys of social relations in cross-national context. Gerontologist 58:488499. https://doi.org/10.1093/geront/gnw204

Antonucci TC, Ajrouch KJ, Abdulrahim S (2015) Social relations in Lebanon: convoys across the life course. Gerontologist 55:825835. https://doi.org/10.1093/geront/gnt209

Ashida S, Heaney CA (2008) Differential associations of social support and social connectedness with structural features of social networks and the health status of older adults. J Aging Health 20:872-893. https://doi.org/10.1177/0898264308324626

Baranowska-Rataj A, Abramowska-Kmon A (2019) Number of children and social contacts among older people: the moderating role of filial norms and social policies. Eur J Ageing 16:95-107. https://doi.org/10.1007/s10433-018-0469-0

Berkman LF, Glass T, Brissette I, Seeman TE (2000) From social integration to health: durkheim in the new millennium. Soc Sci Med 51:843-857. https://doi.org/10.1016/s0277-9536(00)00065-4

Börsch-Supan A et al (2013) Data resource profile: the survey of health, ageing and retirement in Europe (SHARE). Int J Epidemiol 42:1-10. https://doi.org/10.1093/ije/dyt088

Cerino ES, Hooker K, Goodrich E, Dodge HH (2020) Personality moderates intervention effects on cognitive function: a 6-week conversation-based intervention. Gerontologist 60:958-967. https://doi. org/10.1093/geront/gnz063

Colombo B, Piromalli G, Pins B, Taylor C, Fabio RA (2020) The relationship between cognitive reserve and personality traits: a pilot study on a healthy aging Italian sample. Aging Clin Exp Res 32:2031-2040. https://doi.org/10.1007/s40520-019-01386-1

Cornwell B, Schumm LP, Laumann EO, Graber J (2009) Social networks in the NSHAP study: rationale, measurement, and preliminary findings. J Gerontol Ser B-Psychol Sci Soc Sci 64:I47-I55. https://doi.org/10.1093/geronb/gbp042

Dumitrache CG, Rubio L, Cordon-Pozo E (2019) Successful aging in Spanish older adults: the role of psychosocial resources. Int Psychogeriatr 31:181-191. https://doi.org/10.1017/s104161021 8000388

Ellwardt L, van Tilburg T, Aartsen M, Wittek R, Steverink N (2015) Personal networks and mortality risk in older adults: a twentyyear longitudinal Study. PLoS One. https://doi.org/10.1371/journ al.pone.0116731

Erlich B, Litwin H (2019) Personality, age and the well-being of older Europeans. In: Börsch-Supan A, Bristle J, Andersen-Ranberg K, Brugiavini A, Jusot F, Litwin H, Weber G (eds) Health and socioeconomic status over the life course: first results from SHARE waves 6 and 7. De Gruyter, Berlin/Boston, pp 35-41

Grieve R, Kemp N (2015) Individual differences predicting social connectedness derived from Facebook: some unexpected findings. Comput Hum Behav 51:239-243. https://doi.org/10.1016/j.chb. 2015.04.034

Ha JH, Kahng SK, Choi N (2017) Reciprocal effects between health and social support in older adults' relationships with their children and friends. Res Aging 39:300-321. https://doi.org/10.1177/ 0164027515611182

Hall ED, Meng JB, Reynolds RM (2020) Confidant network and interpersonal communication associations with depression in older adulthood. Health Commun 35:872-881. https://doi.org/10.1080/ 10410236.2019.1598616

Huo M, Fuentecilla JL, Birditt KS, Fingerman KL (2020) Empathy and close social ties in late life. J Gerontol Ser B-Psychol Sci Soc Sci 75:1648-1657. https://doi.org/10.1093/geronb/gbz044
Iveniuk J (2019) Social networks, role-relationships, and personality in older adulthood. J Gerontol Ser B-Psychol Sci Soc Sci 74:815826. https://doi.org/10.1093/geronb/gbx120

John OP, Srivastava S (1999) The Big Five trait taxonomy: history, measurement, and theoretical perspectives. In: Pervin LA, John OP (eds) Handbook of personality theory and research, vol 2. Guilford Press, New York, pp 102-138

Kohli M, Hank K, Kunemund H (2009) The social connectedness of older Europeans: patterns, dynamics and contexts. J Eur Soc Policy 19:327-340. https://doi.org/10.1177/1350506809341514

Lang FR, Ludtke O, Asendorpf JB (2001) Validity and psychometric equivalence of the German version of the big five inventory in young, middle-aged and old adults. Diagnostica 47:111-121. https://doi.org/10.1026//0012-1924.47.3.111

Lang FR, Staudinger UM, Carstensen LL (1998) Perspectives on socioemotional selectivity in late life: how personality and social context do (and do not) make a difference. J Gerontol Ser B-Psychol Sci Soc Sci 53:P21-P30. https://doi.org/10.1093/geronb/53B.1. P21

Levinsky M, Litwin H, Lechner C (2019) Personality traits: the tenitem Big Five Inventory (BFI-10). In: Bergmann M, A. S, BörschSupan A (eds) SHARE wave 7 methodology: panel innovations and life histories. MEA, Max Planck Institute for Social Law and Social Policy, Munich, pp 29-34

Lincoln KD, Taylor RJ, Chatters LM (2003) Correlates of emotional support and negative interaction among older black Americans. J Gerontol Ser B-Psychol Sci Soc Sci 58:S225-S233. https://doi. org/10.1093/geronb/58.4.S225

Litwin H (2010) Social networks and well-being: a comparison of older people in Mediterranean and non-Mediterranean countries. J Gerontol Ser B-Psychol Sci Soc Sci 65:599-608. https://doi.org/10. 1093/geronb/gbp104

Litwin H, Sapir EV (2009) Perceived income adequacy among older adults in 12 countries: findings from the survey of health. Ageing Retire Europe Gerontol 49:397-406. https://doi.org/10.1093/ geront/gnp036

Litwin H, Stoeckel KJ (2014) Confidant network types and well-being among older Europeans. Gerontologist 54:762-772. https://doi. org/10.1093/geront/gnt056

Litwin H, Stoeckel KJ, Roll A, Shiovitz-Ezra S, Kotte M (2013) Social network measurement in SHARE wave 4. In: Malter F, BörschSupan A (eds) SHARE wave 4: Innovations and methodology. MEA, Max-Planck-Institute for Social Law and Social Policy, Munich, pp 18-37

Loke SC, Abdullah SS, Chai ST, Hamid TA, Yahaya N (2011) Assessment of factors influencing morale in the elderly. PLoS One. https://doi.org/10.1371/journal.pone.0016490

Lund R, Modvig J, Due P, Holstein BE (2000) Stability and change in structural social relations as predictor of mortality among elderly women and men. Eur J Epidemiol 16:1087-1097. https://doi.org/ 10.1023/a:1010897810514

Macias RL, Gold PB, Jones DR (2013) Age and physical health as predictors of family contact among adults with severe psychiatric illness. Psychiatr Q 84:183-195. https://doi.org/10.1007/ s11126-012-9238-y

Mo F, Zhou J, Kosinski M, Stillwell D (2018) Usage patterns and social circles on Facebook among elderly people with diverse personality traits. Educ Gerontol 44:265-275. https://doi.org/10. 1080/03601277.2018.1459088

Park S, Kim TH, Eom TR (2021) Impact of social network size and contact frequency on resilience in community-dwelling healthy older adults living alone in the republic of Korea. Int J Environ Res Public Health. https://doi.org/10.3390/ijerph18116061 
Phongsavan P et al (2013) Age, gender, social contacts, and psychological distress: findings from the 45 and Up Study. J Aging Health 25:921-943. https://doi.org/10.1177/0898264313497510

Power JEM, Lawlor BA, Kee F (2017) Social support mediates the relationships between extraversion, neuroticism, and cognitive function in older adults. Public Health 147:144-152. https://doi. org/10.1016/j.puhe.2017.02.015

Rafnsson SB, Shankar A, Steptoe A (2015) Longitudinal influences of social network characteristics on subjective well-being of older adults: findings from the ELSA Study. J Aging Health 27:919934. https://doi.org/10.1177/0898264315572111

Rammstedt B, John OP (2007) Measuring personality in one minute or less: a 10-item short version of the big five inventory in English and German. J Res Pers 41:203-212. https://doi.org/10.1016/j. jrp.2006.02.001

Rizzuto D, Mossello E, Fratiglioni L, Santoni G, Wang HX (2017) Personality and survival in older age: the role of lifestyle behaviors and health status. Am J Geriatr Psychiatr 25:1363-1372. https:// doi.org/10.1016/j.jagp.2017.06.008

Schafer MH (2018) (Where) is functional decline isolating? disordered environments and the onset of disability. J Health Soc Behav 59:38-55. https://doi.org/10.1177/0022146517748411

Schnittger RIB, Wherton J, Prendergast D, Lawlor BA (2012) Risk factors and mediating pathways of loneliness and social support in community-dwelling older adults. Aging Ment Health 16:335346. https://doi.org/10.1080/13607863.2011.629092

Schomerus G, Appel K, Meffert PJ, Luppa M, Andersen RM, Grabe HJ, Baumeister SE (2013) Personality-related factors as predictors of help-seeking for depression: a population-based study applying the Behavioral Model of Health Services Use. Soc Psychiatry Psychiatr Epidemiol 48:1809-1817. https://doi.org/10.1007/ s00127-012-0643-1
Schutter N, Koorevaar L, Holwerda TJ, Stek ML, Dekker J, Comijs HC (2020) "Big Five" personality characteristics are associated with loneliness but not with social network size in older adults, irrespective of depression. Int Psychogeriatr 32:53-63. https://doi. org/10.1017/s1041610219000231

Steptoe A, Jackson SE (2018) The life skills of older Americans: association with economic, psychological, social, and health outcomes. Sci Rep. https://doi.org/10.1038/s41598-018-27909-w

Torres JL, Lima-Costa MF, Marmot M, de Oliveira C (2016) Wealth and disability in later life: the english longitudinal study of ageing (ELSA). PLoS One. https://doi.org/10.1371/journal.pone.0166825

Unger JB, McAvay G, Bruce ML, Berkman L, Seeman T (1999) Variation in the impact of social network characteristics on physical functioning in elderly persons: MacArthur studies of successful aging. J Gerontol Ser B-Psychol Sci Soc Sci 54:S245-S251. https://doi.org/10.1093/geronb/54B.5.S245

Van Groenou MIB, Van Tilburg T (2003) Network size and support in old age: differentials by socio-economic status in childhood and adulthood. Ageing Soc 23:625-645. https://doi.org/10.1017/ s0144686x0300134x

von Soest T, Luhmann M, Hansen T, Gerstorf D (2020) Development of loneliness in midlife and old age: its nature and correlates. J Pers Soc Psychol 118:388-406. https://doi.org/10.1037/pspp0 000219

Publisher's Note Springer Nature remains neutral with regard to jurisdictional claims in published maps and institutional affiliations. 